\title{
Pulmonary mucosa-associated lymphoid tissue lymphoma revisited
}

\author{
Raphael Borie ${ }^{1}$, Marie Wislez ${ }^{2,3}$, Martine Antoine ${ }^{3,4}$, Christiane Copie-Bergman $^{5}$, \\ Catherine Thieblemont ${ }^{6}$ and Jacques Cadranel ${ }^{2,3}$

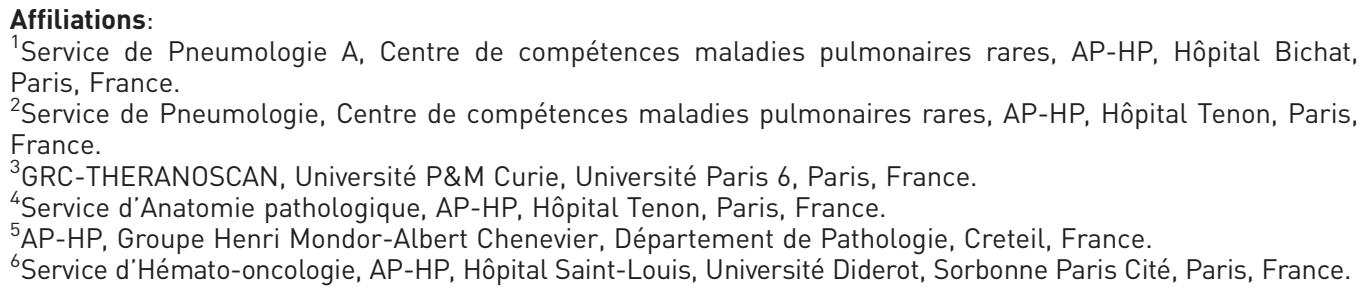

Correspondence: Jacques Cadranel, Service de Pneumologie, Hôpital Tenon, 4 rue de la Chine, F-75970 Paris, France.

E-mail: jacques.cadraneldaphp.fr

ABSTRACT This general review sought to clarify the pathophysiological, diagnostic, prognostic, and therapeutic features of pulmonary mucosa-associated lymphoid tissue (MALT) lymphoma.

MALT lymphoma is the most common pulmonary B-cell lymphoma, which usually occurs in the context of acquired MALT. The disease is slow-growing with an asymptomatic chronic alveolar opacity visible on radiography. Diagnosis requires tissue samples that should be retrieved using minimally invasive techniques, such as bronchoscopy or computed tomography-guided biopsies. The pathophysiology includes cytogenetic abnormalities and autoimmune diseases, whereas an association with a chronic pulmonary infection is still suspected but not yet demonstrated. Disease prognosis is typically excellent and the current available treatments are discussed in this review, including the decision not to treat, surgery, and single- or double-agent chemotherapy.

@ERSpublications

A review clarifying the pathophysiology, diagnosis, prognosis and treatment of pulmonary MALT lymphoma http://ow.ly/Vo47f 


\section{Introduction}

Our previous review pertaining to mucosa-associated lymphoid tissue (MALT) lymphoma was published over 10 years ago [1]. We thus deemed it appropriate to provide an update in view of the recent advances that have been made on this topic, covering disease pathophysiology, diagnostic approaches and novel treatments. B-cell lymphoma may occur in the lungs as a secondary localisation originating from extrapulmonary lymphomas. T-cell lymphomas, however, are uncommon. Primary pulmonary lymphoma (PPL) is defined as a clonal lymphoid proliferation arising from the lung and detected either clinically or radiologically [2, 3]. The most common PPL types are, in order of decreasing frequency [2, 4]: 1) extranodal marginal zone lymphoma (MZL) of MALT; 2) diffuse large B-cell lymphoma (DLBCL); and 3) lymphomatoid granulomatosis.

This general review sought to focus on and clarify the pathophysiological, diagnostic, prognostic, and therapeutic features of pulmonary MALT lymphoma.

\section{Terminology}

MALT lymphoma is the most common type of indolent B-cell PPL (table 1) [5], originating from post-germinal centre memory B-cells. They belong to the group of B-cell MZLs, which also includes nodal and splenic MZL. However, these three MZL subtypes present very distinct clinical, morphological and molecular features [6-10]. MALT lymphomas represent $8 \%$ of adult cases diagnosed with non-Hodgkin lymphoma [11], making them the fourth most common histological subtype after DLBCL, follicular lymphoma and chronic lymphocytic leukaemia/small lymphocytic lymphoma [5].

\section{From MALT to MALT lymphoma}

MALT lymphomas rarely occur at sites where MALT is physiologically abundant, e.g. the Peyer's patches of the terminal ileum, instead they are most frequently found rather at sites usually devoid of MALT such as the stomach, salivary glands, lungs and thyroid.

\section{Marginal zone and bronchial mucosa-associated lymphoid tissue}

The histological features of the marginal zone of lymphoid follicles was first described in the spleen [12], and later recognised in other sites such as the Peyer's patches and in lymph nodes. Functionally, marginal zone B-lymphocytes are memory B-cells, and are involved in T-cell-dependent or -independent immune responses. MALT is a lymphoid tissue specialised in defending the mucosa [2], first described in the gastrointestinal tract in animal models and then later in the ileum in humans. MALT is composed of four compartments: 1) organised mucosal lymphoid tissue that consists of reactive lymphoid follicles, which form Peyer's patches when concentrated in the terminal ileum; 2) the lamina propria; 3) intraepithelial lymphocytes; and 4) the mesenteric lymph nodes (figure 1) [2].

Peyer's patches are mucosal non-encapsulated aggregates of lymphoid tissue, the structure of which is similar to that of nodal lymphoid follicles. The marginal zone surrounds the mantle zone of the follicle and extends towards the mucosal surface. It is composed of centrocyte-like cells, which resemble monocytoid cells and express pan-B-antigens, surface IgM and surface IgA1, whereas they are negative for surface IgD, CD5 and CD10. This differentiates them from naïve B-cells, which do express surface IgD. Marginal zone B-cells have mutated Ig variable region genes and the majority are post-germinal centre memory B-cells. The B-cells found in MALT retain the ability to return to the tissues in which they

\section{TABLE 1 Primary pulmonary lymphoma according to the World Health Organization classification of tumours of haematopoietic and lymphoid tissues}

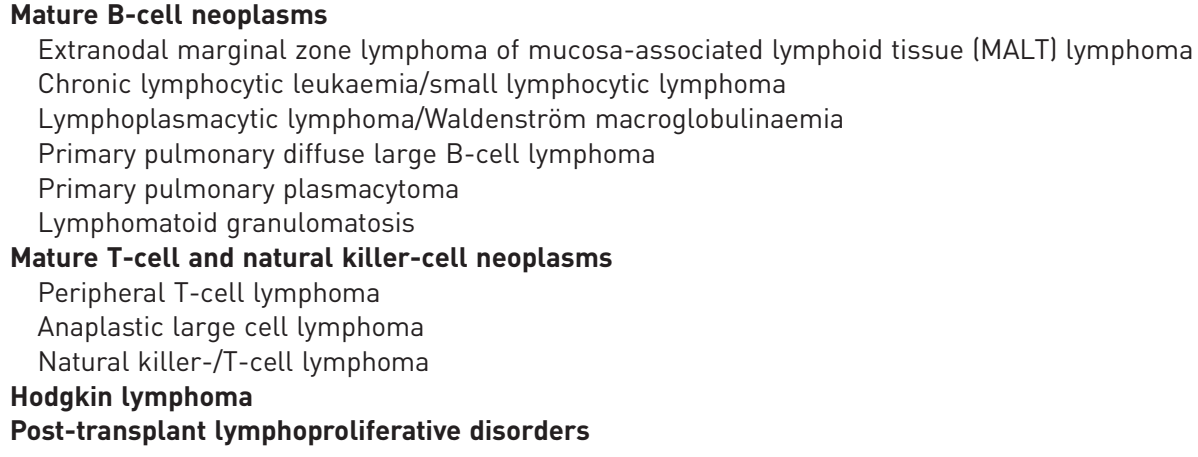



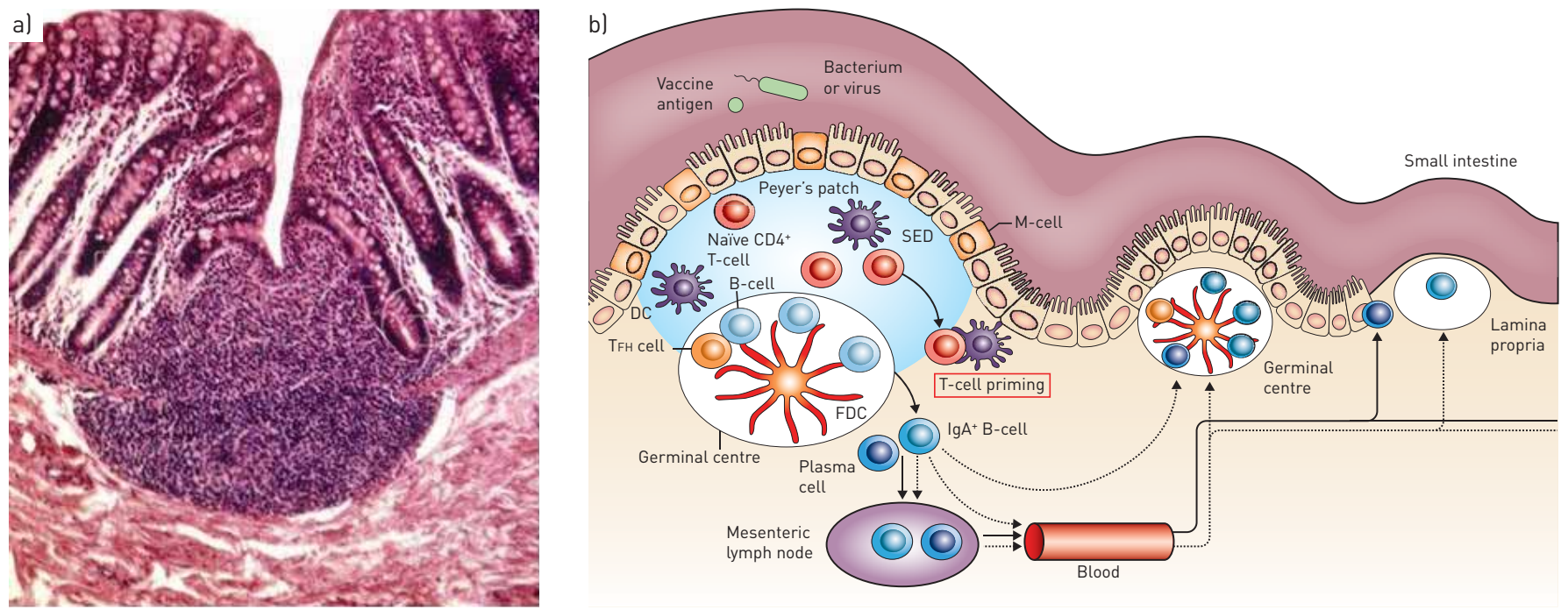

FIGURE 1 a) Normal small intestine histology with Peyer's patches. b) Initiation of the immune response in the gut: antigens are taken up by microfold (M)-cells and process to the subepithelial dome (SED)-resident dendritic cells (DCs) in Peyer's patches. T-follicular helper (TFH) cells interact with B-cells and follicular dendritic cell (FDC) thus forming a germinal centre. Antigen specific plasma cells and memory B-cells are generated and migrate through the blood and mesenteric lymph nodes [94]. Reproduced from [104] with permission from the publisher.

underwent antigen stimulation, probably by means of surface integrin expression. Marginal zone B-cells can also form clusters of intraepithelial B-cells. The lamina propria contains IgA-secreting plasma cells, macrophages, and B- and T-lymphocytes. The intraepithelial lymphocytes predominantly found in the jejunum consist of CD8 T-cells that express the human mucosal lymphocyte-1 antigen (HML-1/CD103). The basic structure of mesenteric lymph nodes is the same as that of peripheral lymph nodes, with a prominent marginal zone. Memory B-cells from post-germinal centres circulate in the peripheral blood and include cells from the marginal zone of the spleen, lymph nodes and MALT.

Bronchus-associated lymphoid tissue (BALT) was first described in fetal and neonatal lungs affected by pulmonary infections of undetermined nature [2]. BALT can also be found in follicular bronchiolitis and can be associated with various autoimmune disorders, such as Sjögren's syndrome, yet is not found in normal lungs. The stomach is the most commonly-affected organ in terms of MALT lymphoma, and several features of stomach MALT lymphoma can be extrapolated to MALT lymphoma in other locations like the lungs.

\section{MALT chronic antigen stimulation}

Lymphomas of the marginal zone are generally associated with chronic antigen stimulation, regardless of whether the antigens are auto-antigens or of microbial origin (figure 2) [12]. This is an unusual form of lymphoproliferation, in which the infectious agent does not infect or directly transform the lymphoid cells, unlike lymphomas associated with Epstein-Barr virus, human herpesvirus 8 or human T-cell leukaemia virus 1 [13]. In MZLs, the infectious agent increases the risk of lymphomatous transformation by chronically stimulating B-lymphocyte proliferation. In cases of chronic antigen stimulation, such as Helicobacter pylori infection, MALT develops in the stomach and can later undergo lymphomatous transformation starting with the B-lymphocytes in the marginal zone. In the original observation of gastric MALT lymphoma, the malignant B-cell clone process initially required the presence of the $H$. pylori antigen in order to proliferate, with $\mathrm{H}$. pylori being detected in almost $90 \%$ of gastric biopsies from patients with gastric MALT lymphoma [14, 15], and its eradication leading to complete and prolonged disease remission in $60-80 \%$ of early-stage gastric MALT lymphoma cases. H. pylori eradication has also been reported to be effective in localised gastric DLBCL $[12,14,16]$. However, some recent studies show an increasing rate of $H$. pylori-negative patients of up to $30-50 \%$ of gastric MALT lymphoma cases [17]. The reason for this remains unclear; the liberal use of antibiotics in patient with suspected $H$. pylori infection or symptoms might be a potential explanation for a shift in MALT lymphoma characteristics in the near future.

Other infectious agents have been suggested as possible causes of MALT lymphoma at other sites [12, 18, 19]. A causal relationship has been suggested between Campylobacter jejuni infection and small intestine MALT lymphoma, formerly known as $\alpha$-chain disease or Mediterranean lymphoma, as well as between hepatitis $C$ virus infection and some cases of splenic MZL. Several studies have also found associations, although no 


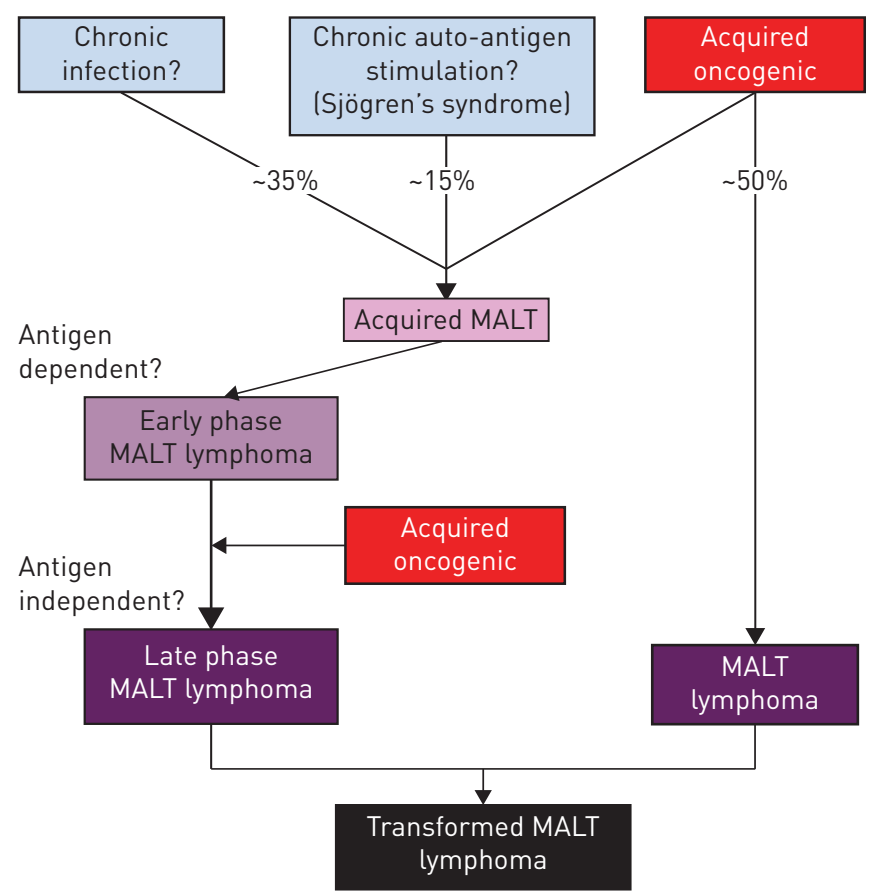

FIGURE 2 Pathophysiology of pulmonary mucosa-associated lymphoid tissue (MALT) lymphoma. Development of MALT has been demonstrated to be related to chronic infection in the gut, but not yet in the lung, and could be related to chronic auto-antigen stimulation (i.e. Sjögren's syndrome). Almost $50 \%$ of pulmonary MALT lymphomas show cytogenetic abnormalities and become independent from antigen stimulation if any.

proven causal relationship, between Borrelia burgdorferi (the agent that causes Lyme disease) infection and skin MALT lymphoma, and between Chlamydophila psittaci and ocular adnexal MALT lymphoma.

A causative antigen associated with MALT lymphoma in the lungs has not yet been identified. One study used PCR in order to detect DNA traces of Chlamydophila pneumoniae, Chlamydia trachomatis, C. psittaci or Mycoplasma pneumoniae in tissues from patients with pulmonary MALT lymphoma $(\mathrm{n}=69)$. The results were compared with control specimens of other pulmonary lymphoproliferative disorders $(\mathrm{n}=30)$ and non-lymphoproliferative disorders $(\mathrm{n}=44)$ [20]. In this study, chlamydiaceae DNA was detected more frequently in MALT tissue than in samples taken from patients with non-lymphoproliferative disorders, although the difference was not statistically significant. Mycoplasma DNA was not detected. In addition, a recent multicentre European study using a $16 \mathrm{~S}$ ribosomal RNA-based approach found DNA from Achromobacter xylosoxidans in 57 out of 124 pulmonary MALT lymphomas versus 15 out of 82 controls $(\mathrm{p}=0.004)$ [21]. Further studies are now required to prove the causal relationship between this pathogen and pulmonary MALT lymphoma. Using a non-targeted approach, our team assiduously pursues its research in this field using modern microbiology techniques. Powerful tools have been developed for both DNA and RNA sequencing [22], enabling the analysis of all the DNA and RNA present in a given sample, which could provide some evidence of a specific pathogen's presence being associated with pulmonary MALT lymphoma [23].

Chronic antigen stimulation may also be of autoimmune origin (figure 2). MALT lymphomas in the salivary and thyroid glands have been more commonly observed in patients with autoimmune disease, Sjögren's syndrome or Hashimoto's thyroiditis. A meta-analysis involving 29423 patients confirmed that those with Sjögren's syndrome or systemic lupus erythematosus exhibited an increased risk of MZL [24]. Primary or secondary Sjögren's syndrome was reported to be associated with a 6.5 -fold increased risk of any type of lymphoma, a 1000-fold increased risk of salivary gland MALT lymphoma, and a 5-fold increased risk of lymphoma at other extranodal sites. Systemic lupus erythematosus was associated with a 2.7-fold increased risk of any type of lymphoma, and a 12.9-fold increased risk of extranodal lymphoma. Disorders involving chronic antigen stimulation, such as systemic lupus erythematosus, multiple sclerosis, Hashimoto's thyroiditis, and, in particular, Sjögren's syndrome, are all recognised risk factors for developing pulmonary MALT lymphoma [24].

Due to environmental risk factors, bakers and oil workers display an increased risk of ocular adnexal and cutaneous MALT lymphomas, respectively [25]. However, this risk has not yet been demonstrated in pulmonary MALT lymphomas. 


\section{Cytogenetic abnormalities}

The cytogenetic abnormalities that characterise and promote MALT lymphomas have been known for several years (table 2 and figure 2). Both the frequency and type of cytogenetic abnormality vary depending on the lymphoma's site, and may also be related to the patient's origin. By contrast with other forms of lymphoma, MALT lymphomas are not characterised by a diagnostic genetic aberration, with the exception being $\mathrm{t}(11 ; 18)(\mathrm{q} 21 ; \mathrm{q} 21)$ API2-MALT1 discussed below, but rather display a variety of genetic features. Cytogenetic abnormalities are most frequently found in the lungs, and translocations are the most common type of alterations, with $\mathrm{t}(11 ; 18)(\mathrm{q} 21 ; \mathrm{q} 21)$ being the most common translocation found and specific to MALT lymphomas [26]. This translocation is detected in $42 \%$ of pulmonary cases, $22 \%$ of gastric cases and $15 \%$ of intestinal cases, though it is absent in most cases of thyroid, salivary gland and liver MALT lymphoma [27, 28]. In gastric MALT lymphoma, the $t(11 ; 18)(\mathrm{q} 21 ; \mathrm{q} 21)$ translocation has been associated with lymph node dissemination and resistance to $H$. pylori-targeting antibiotics. As a consequence of this, the API2 gene (apoptosis inhibitor 2), located on chromosome 11, fuses with the MALT1 gene (MALT lymphoma-associated translocation), located on chromosome 18, resulting in the production of a chimeric protein: AP12-MALT1. Other translocations include the $\mathrm{t}(1 ; 14)(\mathrm{p} 22 ; \mathrm{q} 32)$ BCL10-IgH, $\mathrm{t}(14 ; 18)(\mathrm{q} 32 ; \mathrm{q} 21)$ IgH-MALT1, two rarer translocations that have been reported in the stomach, lung and skin for the $\mathrm{t}(1 ; 14)$ and in the liver, lung and ocular adnexa for the $t(14 ; 18)$ [27]. In each case, the translocation results in transcriptional dysregulation of the modified gene and overexpression of BCL10 and MALT1, respectively, in the tumour cells. Another translocation, $\mathrm{t}(3 ; 14)(\mathrm{p} 14.1 ; \mathrm{q} 32)$ FOXP1-IgH, has recently been described, but is not specific for MALT lymphomas since it has also been reported in DLBCLs. Its presence excludes $\mathrm{t}(11 ; 18)(\mathrm{q} 21 ; \mathrm{q} 21)$. FOXP1 protein is also overexpressed in MALT lymphomas with trisomy 3, suggesting that increased gene copy number may be another mechanism of deregulated gene expression.

All the translocations listed above, with the exception of $\mathrm{t}(3 ; 14)(\mathrm{p} 14.1 ; \mathrm{q} 32)$, result in constitutive activation of the nuclear factor- $\kappa \mathrm{B}$ signalling pathway. The aforementioned translocations can be detected either by interphase fluorescent in situ hybridisation (FISH) in formalin-fixed paraffin-embedded (FFPE) tissue sections or alternatively by reverse transcriptase PCR assays in frozen tumour samples [26]. Other cytogenetic abnormalities associated with MALT lymphoma are trisomy 3 and 18 [26]. Aneuploidy is rarely associated with $\mathrm{t}(11 ; 18)$. Although diagnosis of API2-MALT1 translocation in gastric MALT lymphoma is associated with resistance to antibiotic eradication of $H$ pylori, and to more frequent disseminated disease at diagnosis, the prognostic or predictive value of cytogenetic abnormalities have not been assessed in pulmonary MALT lymphoma [29]. It has also been suggested that presence of API2-MALT1 translocation is associated with a better response to chemotherapy (see later) [29].

Finally, MALT lymphoma could develop as a result of both cytogenetic abnormalities and antigenic stimulation. Illustrating this point, a mouse model simulating BCL10 or API2-MALT overexpression

TABLE 2 Main cytogenetic abnormalities involved in marginal zone lymphoma

\begin{tabular}{|c|c|}
\hline Cytogenetic abnormality & Site (frequency) \\
\hline $\mathrm{t}(11 ; 18)(\mathrm{q} 21 ; \mathrm{q} 21)$ API2-MALT1 & $\begin{array}{l}\text { Lung }(30-50 \%) \\
\text { Intestine }(\sim 40 \%) \\
\text { Stomach }(5-\sim 30 \%) \\
\text { Ocular adnexa }(0-5 \%)\end{array}$ \\
\hline $\mathrm{t}(14 ; 18)(\mathrm{q} 32 ; \mathrm{q} 21) \lg H-M A L T 1$ & $\begin{array}{l}\text { Ocular adnexa, skin, salivary glands and liver (frequent) } \\
\text { Lung }(10 \%) \\
\text { Stomach (rare) }\end{array}$ \\
\hline $\mathrm{t}(1 ; 14)(\mathrm{p} 22 ; q 32) B C L 10-\lg H$ & $\begin{array}{l}\text { Stomach (5\%) } \\
\text { Lung (rare) }\end{array}$ \\
\hline $\mathrm{t}(3 ; 14)(\mathrm{p} 14.1 ; q 32)$ FOXP1-IgH & $\begin{array}{l}\text { All sites }(10 \%) \\
\text { Thyroid }(50 \%) \\
\text { Ocular adnexa }(20 \%) \\
\text { Skin }(10 \%)\end{array}$ \\
\hline Trisomy $3,12,18$ & $\begin{array}{l}\text { Intestine } \\
\text { Salivary glands } \\
\text { Ocular adnexa }\end{array}$ \\
\hline
\end{tabular}

Information from [15]. 
demonstrated the development of marginal zone hyperplasia without lymphoma. However, the mice undergoing API2-MALT1 overexpression developed lymphoma following antigenic stimulation with Freund adjuvant [30-32].

\section{Epidemiology, clinical tests and imaging}

PPLs are rare clinical entities, representing only $0.5-1 \%$ of lung neoplasia cases (figure 3). MALT lymphomas represent over $80 \%$ of PPL cases, constituting the most common type of pulmonary lymphoma [33-35]. PPL onset usually occurs at $~ 50-60$ years of age, very occasionally affecting those under 30 years old [1]. Smoking rates $(\sim 35 \%)$ were not found to be higher among people that develop PPL than in the general population [35], and women were affected just as often as men. The presence of an immune system disorder was identified as a predisposing factor for developing a MALT lymphoma, with a recent study reporting that $16 \%$ of patients presented an autoimmune disease at the time of diagnosis [35].

In nearly half of MALT lymphoma cases the patients are asymptomatic at diagnosis, and investigations are initiated solely due to an abnormal chest radiograph. If symptoms are present, they are mostly nonspecific and commonly include cough, minimal dyspnoea and chest pain, haemoptysis is also sometimes reported. Crepitant rales are detected by pulmonary auscultation in less than $20 \%$ of cases. While general symptoms like fever and weight loss are observed in less than a quarter of MALT lymphoma patients, these are particularly associated with aggressive disease forms [1].

On radiological examination, MALT lymphomas typically manifest as a chronic alveolar localised opacity, less than $5 \mathrm{~cm}$ in diameter, and are associated with air bronchogram in nearly $50 \%$ of cases [36-40]. Computed tomography (CT) (figure 4), which is more sensitive than standard radiography, has demonstrated that the majority of MALT lesions are bilateral (60-70\% of cases) and multiple (70-77\% of cases) $[41,42]$. There is no topographic predominance. Opacities contain a clear patch within each lesion, corresponding to the intact bronchial lumen. MALT lymphomas are often diagnosed based on the presence of distended bronchi within lesions [42]. The most frequent patterns are consolidations $(\sim 55 \%)$, nodules $(\sim 55 \%)$ and masses $(\sim 50 \%)$, and $\sim 85 \%$ of the patients have airways within the lesions. Micronodules ( $\sim 20 \%)$, ground-glass opacities $(\sim 25 \%)$ and septal lines $(\sim 10 \%)$ are less frequent [36-38]. Ultimately, the CT scan pattern may be a solitary pulmonary nodule and even more rarely a cystic or a cavitary lesion. Cystic lung lesions are frequently associated with associated amyloid or light chain deposition and cavitary lesions suggest a higher grade lymphoma [43-45]. Hilar or mediastinal lymphadenopathy may also be found

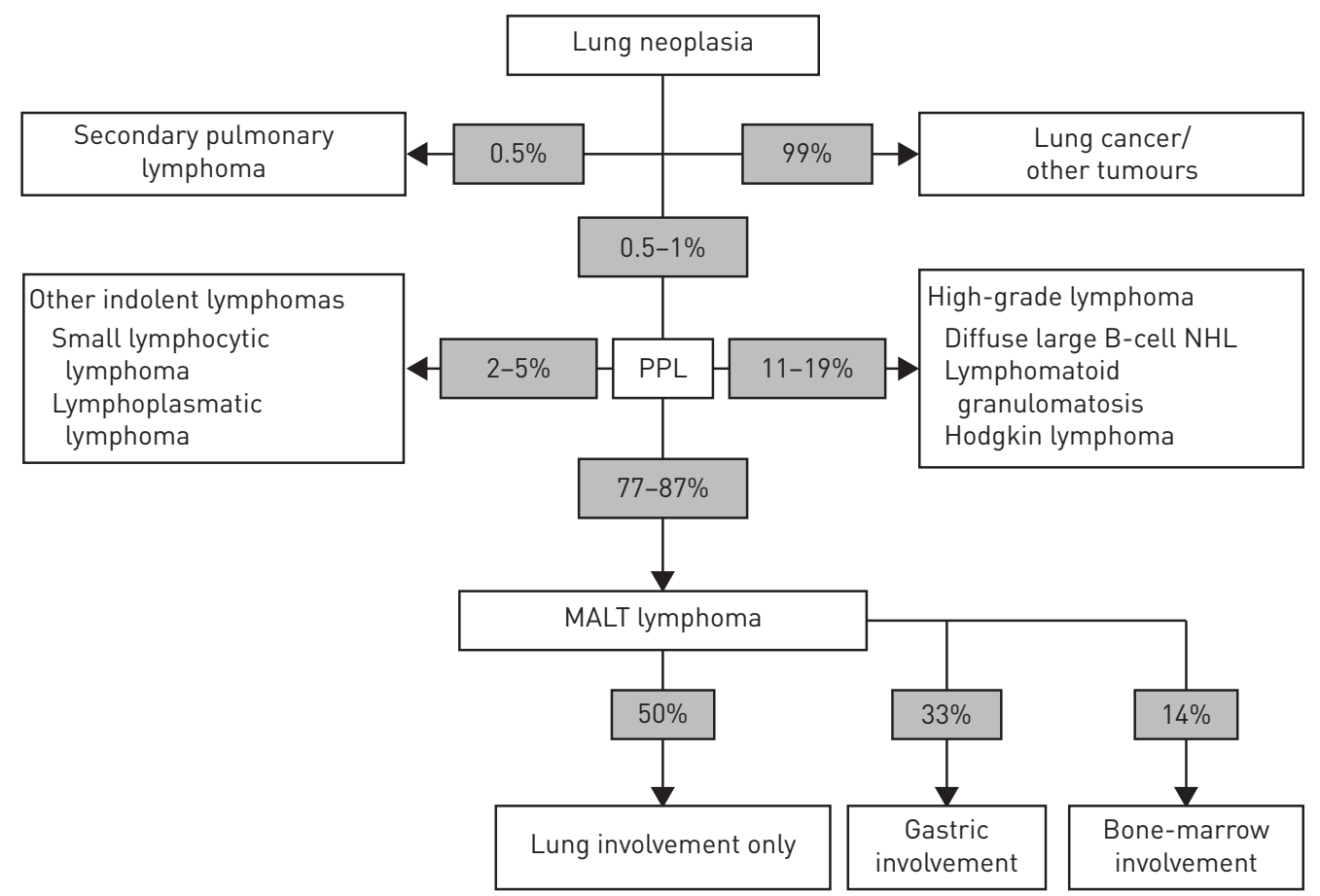

FIGURE 3 Respective percentages of lung neoplasia. Primary pulmonary lymphomas (PPL) are rare; with mucosa-associated lymphoid tissue lymphomas being the most common type of PPL. NHL: non-Hodgkin lymphoma. 

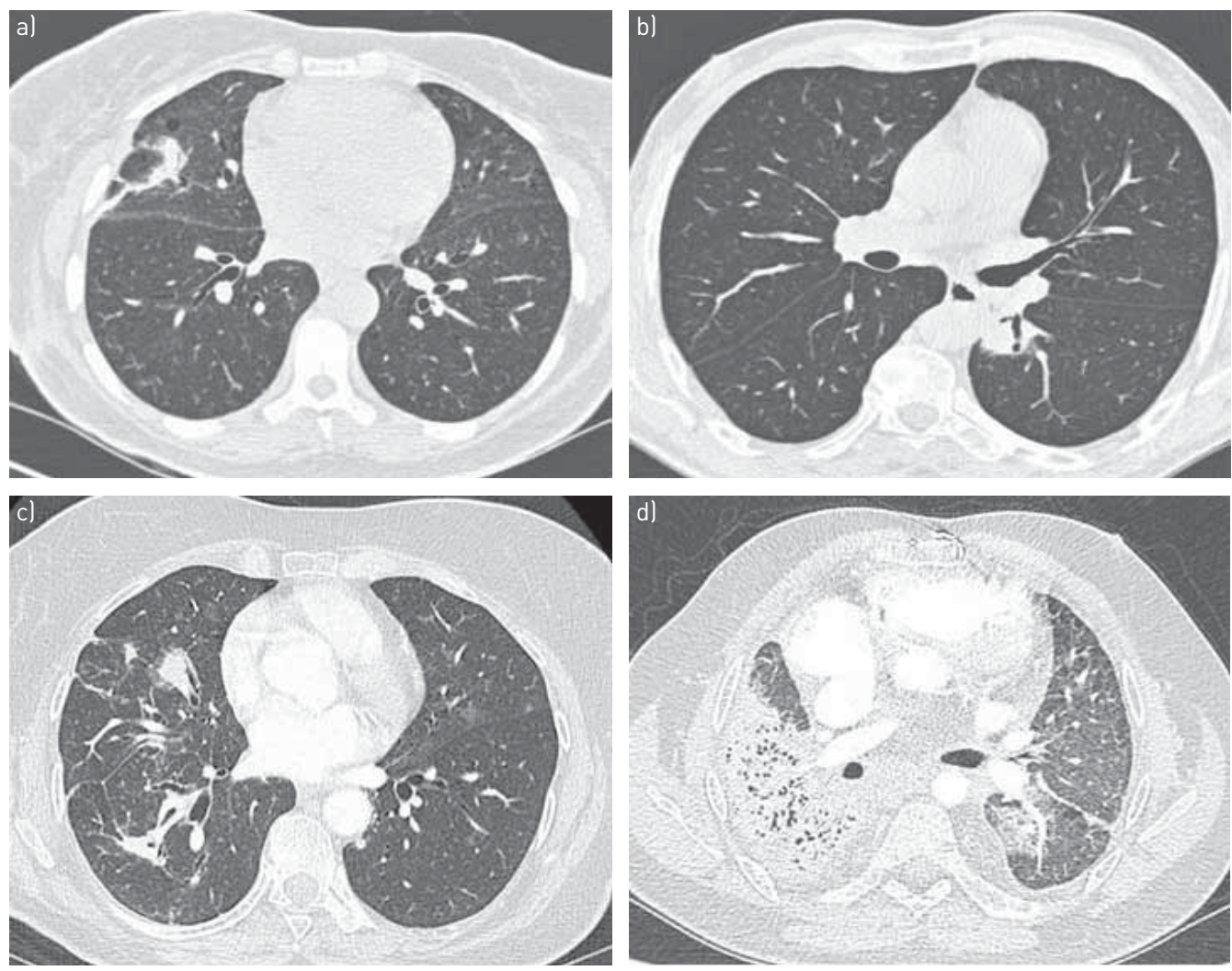

FIGURE 4 a-d) Representative computed tomography images of the different patterns that are all confirmed to be pulmonary mucosa-associated lymphoid tissue lymphoma. Localised alveolar opacities in the same patient in al the middle lobe and b) the left lower lobe. c) Diffuse alveolar opacities in the right upper lung associated with diffuse gound-glass opacities. d) Consolidation of the right upper lung with airways within the lesion associated with diffuse reticulations and ground-glass opacities.

on the CT scan in $\sim 15 \%$ of cases, but are usually $<1.5 \mathrm{~cm}$ and a mild pleural effusion in $\sim 10 \%$ of cases [36]. The mean time between the initial abnormal clinical or radiological findings and diagnosis is 9 months, although this may vary widely from 15 days to 8 years [35-39].

On the clinical level, the challenge is to correctly diagnose MALT lymphoma based on radiological findings of chronic diffuse or localised alveolar opacities, which can correspond to several different aetiologies (table 3).

\section{Diagnostic approach}

In cases where patients present with pulmonary lesions and when a MALT lymphoma is suspected, several approaches may be required to obtain sufficient information for a correct diagnosis, in order to exclude other inflammatory conditions and malignancies as well as accurately classify the exact lymphoma subtype. Tissue biopsy is the gold standard for diagnosis. FFPE biopsy samples are used for histological assessment and immunohistochemistry, while frozen samples are employed for molecular genetic analysis

TABLE 3 Main aetiologies to be considered in cases of chronic single or multiple alveolar opacities

\section{Frequent causes}

Bacterial or viral pneumonia, slow to resolve

Organising pneumonia

Tuberculosis

Pulmonary infarction

\section{Less frequent causes}

Lepidic adenocarcinoma

Pseudo-alveolar sarcoidosis

Lymphoma

Bacterial pneumonia involving slow-growing organisms (nocardiosis, actinomycosis) 
(PCR for immunoglobulin gene rearrangements). Biopsy samples can also provide cells for cytological examination and flow cytometry. The goal of the diagnostic approach is to use minimally invasive techniques, such as bronchoscopy and CT-guided needle biopsy, in order to limit the number of invasive procedures, such as thoracotomy with surgical biopsies.

\section{Contribution of bronchoscopy with biopsies and bronchoalveolar lavage}

While the macroscopic findings on bronchoscopy are usually normal [36], abnormalities like inflammatory mucosa and bronchial stenosis may be observed [36]. Polypoid endobronchial lesions are very rare and usually point towards a small cell non-Hodgkin lymphoma. Bronchial and transbronchial biopsies are more fruitful when carried out on endobronchial lesions or guided by the topography of abnormalities mapped by CT scanning [36]. The sensitivity of bronchial and transbronchial biopsies in detecting MALT lymphoma have been reported to be 31 and $88 \%$, respectively (figure 5) [35].

Bronchoalveolar lavage (BAL) performed during bronchoscopy may also aid in diagnosing chronic alveolar opacities. This technique can indicate the absence of tumour epithelial cells that are found in other malignancies, e.g. lepidic adenocarcinoma (formerly termed bronchioloalveolar carcinoma), or the presence of pathogens pointing towards a chronic infection. The presence of lymphocytic alveolitis can also be indicative of PPL [46], although this lymphocytosis often presents a T-cell phenotype and does not appear to be specific to PPL, unless the B-lymphocyte level is greater than $10 \%[36,46,47]$. Lymphocytes obtained by BAL may also include monocytoid, centrocyte-like or plasmacytoid cells. The diagnostic value of B-lymphocyte alveolitis is at its most significant if the clonality can be demonstrated by illustrating the

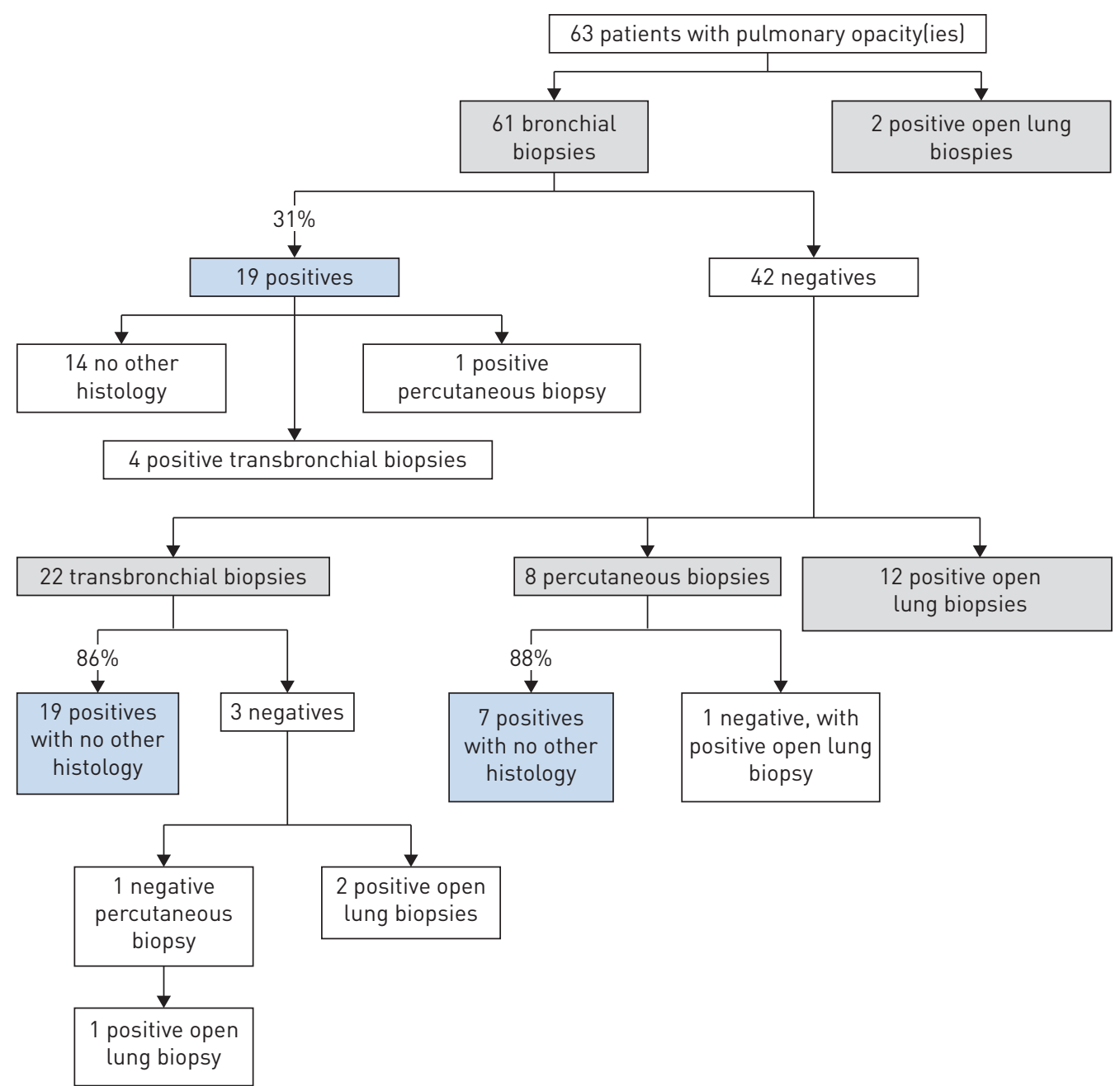

FIGURE 5 The diagnosis strategy adopted in a retrospective series of 63 patients with pulmonary opacity. Step 1: 61 bronchial and transbronchial biopsies during bronchoscopy; step 2: computed tomography (CT)-guided percutaneous transparietal biopsies. In the absence of a previous diagnosis, the final step was an open lung biopsy. Reproduced from [35]. 
clonal rearrangement of immunoglobulin genes using either molecular biology techniques or light chain restriction by flow cytometry [48-52]. Nevertheless, a negative result does not exclude a MALT lymphoma diagnosis. In a recent study, $84 \%$ of patients with MALT lymphoma $(n=35)$ exhibited over $15 \%$ lymphocytic alveolitis. B-lymphocytes accounted for more than $10 \%$ of the alveolar lymphocytes in cases where phenotyping was available, and the B-cell clone was identified in $71 \%$ of cases [53]. Moreover, the translocation $\mathrm{t}(11 ; 18)$ (q21;q21), which is specific to MALT lymphomas, can be evidenced in BAL [54]. These data confirm that BAL could represent a powerful diagnostic tool that is currently underemployed in clinical practice.

If no specific lesion is identified by bronchoscopy, CT-guided aspiration and biopsy must be considered. This technique is particularly appropriate for peripheral nodules or masses. The sensitivity of this test has been reported to be $80 \%$ (figure 5) [35]. Diagnostic surgery may then be performed as a last resort. This invasive approach requires significant effort, expense and post-biopsy recovery time for the patient; however, it does offer the advantage of providing larger biopsy samples than less invasive procedures. Lymphomas can be morphologically and immunophenotypically complex, they are sometimes associated with reactive elements such as non-neoplastic reacting T-cells, granulomas, amyloid or fibrosis, rendering any diagnosis difficult using just small biopsy samples. When a localised lesion is present, a surgical approach provides the opportunity for radical treatment to be performed at the same time as the biopsy procedure (see the section on Prognosis and treatment).

It has been reported that a diagnosis of MALT lymphoma has been made using endobronchial ultrasound or endoscopic ultrasound in experienced hands, with flow cytometry performed on samples [55]. Although endobronchial ultrasound has been reported to be a good diagnosis tool for large B-cell and Hodgkin lymphoma [55-57], this approach seems unsuitable in pulmonary MALT lymphoma as mediastinal lymphadenopathies are infrequent $(\sim 15 \%)$ and of a small size $(<1.5 \mathrm{~cm}$ diameter $)$ [35]. Transbronchial cryobiopsy has recently been developed and is actually discussed in the diagnosis algorithm for diffuse interstitial lung diseases [58]. As histological confirmation usually comes from small samples that may be retrieved from transbronchial or transthoracic biopsies [35], cryobiopsy could be discussed in experienced teams in an attempt to avoid surgical biopsy [59].

\section{Pathological diagnostic criteria}

The diagnosis of MALT lymphoma is established based on histological analysis of tumour tissue. The typical macroscopic characteristics of MALT lymphoma are a whitish mass, which is poorly delimited and soft, not dissimilar in texture to the cut surface of a lymph node affected by the lymphoma. Rare cases of focally cystic MALT lymphoma have been observed.

The histological features of MALT lymphoma are the presence of lymphoid infiltrate expanding the marginal zone of reactive lymphoid follicles composed of small cells with a variable cytological appearance including small round lymphocytes, centrocyte-like cells or monocytoid cells. Scattered centroblasts are present. Plasma cell differentiation is often seen in the lung. The tumour cells infiltrate the bronchiolar or the alveolar epithelium resulting in lymphoepithelial lesions. Follicular colonisation by the tumour cells may be observed [34, 37, 60-62]. Cohesive sheets of large B-cells must suggest the diagnosis of DLBCL associated with MALT lymphoma.

Plasma cells may be numerous and may or may not show light chain restriction. Tumour cell infiltrates may also be seen along the bronchovascular bundles and interlobular septa in the masses' periphery, such as the alveolar and bronchiolar walls [63]. The density of MALT lymphoma infiltration often produces a widening of the alveolar walls, and collapses the residual alveolar lumens. The airways are often left intact, which correlates with air bronchograms observed on CT scans (figure 6). More unusual forms of MALT lesions may include amyloid deposits or granulomatous reaction, vascular invasion [62-66], or fibrosis of varying degrees [63], although these are not key diagnostic features.

\section{Contribution of immunohistochemistry}

Immunohistochemistry analysis of FFPE tissue sections is mandatory to confirm the diagnosis of MALT lymphoma and to exclude reactive follicular hyperplasia or secondary localisation to the lung of a nodal B-cell lymphoma. Tumour cells express CD20 and CD79a B-cell antigens and expand along bronchovascular bundles and interlobular septa (figure 7) [34, 37, 39, 40, 60-63, 67]. They are CD5 negative which allows exclusion of the diagnosis of mantle cell lymphoma or chronic lymphocytic leukaemia [46]. Residual lymphoid follicles may be highlighted with the staining of $\mathrm{CD} 21^{+} \mathrm{CD} 23^{+}$residual follicular dendritic cells $[35,45,47]$. Small reactive T-lymphocytes (CD3) can also be detected within the parietal alveolar infiltrate and around the peribronchiolar nodules [61, 63]. Plasma cell differentiation is further explored with immunostaining with anti-kappa and anti-lambda antibodies, and is very useful to distinguish MALT lymphoma with monotypic plasma cells from a reactive plasma cell infiltrate. Morphology and 

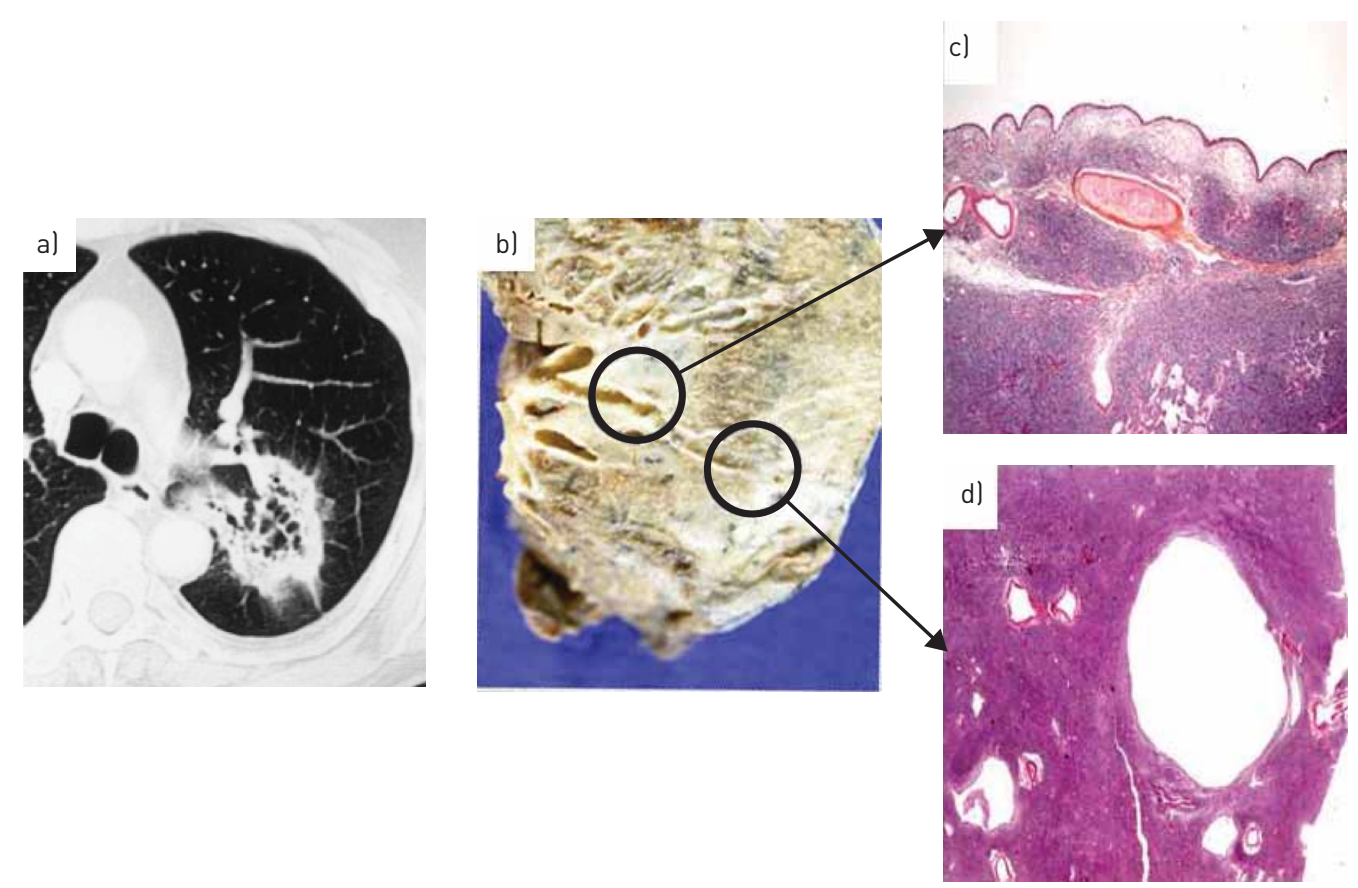

FIGURE 6 Representative section of a computed tomography (CT) image, and lung macroscopic and microscopic examinations obtained from a patient with pulmonary mucosa-associated lymphoid tissue (MALT) lymphoma. a) The CT image shows alveolar localised opacity with distended bronchi within lesions. b) Macroscopic examination shows a whitish mass that is revealed to be MALT lymphoma in the microscopic examination (haematoxylin and eosin stain, $25 \times$ magnification) with a representative section of c) bronchial wall and d) bronchial distention due to alveolar collapse.

immunohistochemistry allow the exclusion of lung localisation of mantle cell, follicular, lymphoplasmacytic or lymphocytic lymphomas [61, 63]. The proliferative index is usually low (Ki-67 <10\%).

\section{Contribution of molecular biology}

Current molecular biological techniques involve PCR-based methods using frozen or FFPE tissue samples (sometimes with prior microdissection) to determine B-cell clonality. This analysis is very useful for cases where the morphological and immunohistochemical features are not sufficient to establish the diagnosis of MALT lymphoma. Chromosomal translocations are detected either by reverse transcriptase PCR or by interphase FISH on FFPE tissue sections using break apart probes for the MALT1 gene.

FISH techniques can also detect extra copies of chromosomes 3, 8 and 18, which are common in MALT lymphomas. As an alternative to immunohistochemistry with anti-kappa and anti-lambda antibodies, chromogenic in situ hybridisation with kappa and lambda probes may also be used to determine if the tumoral plasma cell component shows light chain restriction (clonal).

However, molecular biology is not sufficient for the diagnosis of MALT lymphoma even in presence of a specific translocation. Moreover, specific translocations are not actually treated by a targeted therapy.

\section{Differential diagnosis}

The primary challenge in terms of histology, particularly when using a small specimen, is to distinguish MALT lymphoma from: 1) diffuse lymphoid hyperplasia and lymphocytic interstitial pneumonia; 2) follicular bronchiolitis and chronic aspecific inflammatory reaction; or 3) other low grade B-cell lymphomas, as previously discussed, and 4) chronic nonspecific inflammatory reaction [62, 68]. The distinction of MALT lymphoma from organised pneumonia and/or nonspecific interstitial pneumonia relies mainly on histopathological features and the demonstration of an abundant small B-cell infiltrate extending beyond the reactive lymphoid follicles with a characteristic lymphangitic pattern of infiltration spreading along bronchovascular bundles and interlobular septa, features that may be overlooked in small biopsy specimens. While lymphoepithelial lesions may be observed in reactive conditions, detecting an intraepithelial lymphocytic infiltrate with a dual CD20/CD43-positive phenotype is nonetheless a strong indicator of MALT lymphoma [62]. 

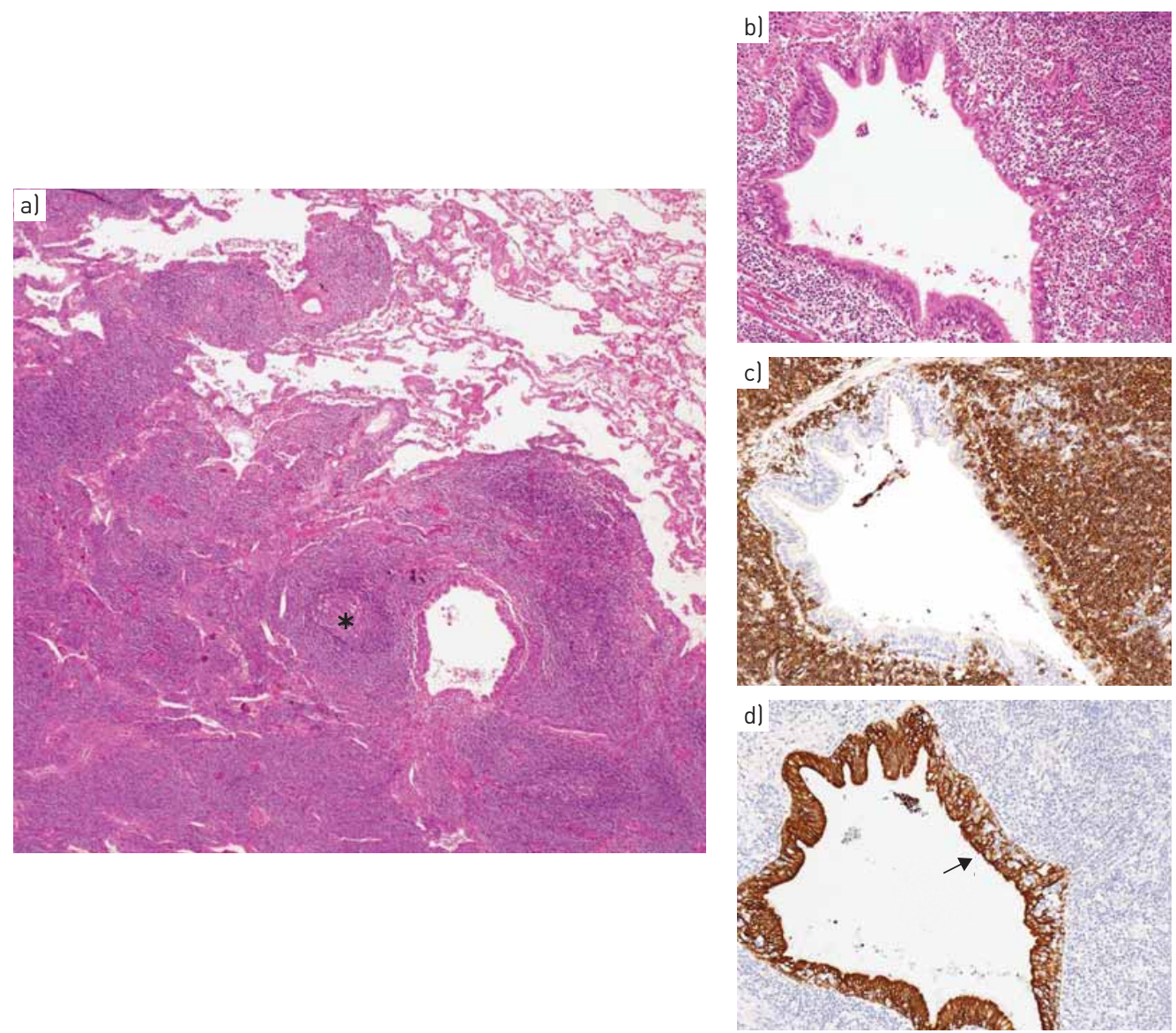

FIGURE 7 Representative histology of pulmonary mucosa-associated lymphoid tissue (MALT) lymphoma. a) Low magnification showing a nodular lymphoid infiltrate of the lung, expanding the marginal zone of reactive lymphoid follicles $(*)$ infiltrating the bronchiolar epithelium (haematoxylin and eosin stain, 25x magnification). b) Small lymphoid cells forming lymphoepithelial lesion (haematoxylin and eosin stain, 25x magnification) with c) a CD20 immunophenotype (25× magnification). d) Lymphoepithelial lesions (arrow) are highlighted with anti-cytokeratin AE1/AE3 immunostaining (25× magnification).

A unique nodular presentation may correspond to plasma cell granuloma, an inflammatory myofibroblastic tumour or IgG4 syndrome. IgG4-related disease may be distinguished from pulmonary MALT lymphoma by the presence of abundant IgG4-positive cells admixed with a moderate amount of eosinophils, storiform-type fibrosis, obliterative phlebitis and arteritis. This diagnosis is supported by an $\mathrm{IgG}^{+} / \mathrm{IgG}^{+}$cell ratio of $>40 \%$ evaluated on tissue sections and elevated serum IgG4 concentration. However, a potential relationship between IgG4-related disease and extranodal MZL has been recently discussed in the literature, based on rare observations of ocular adnexal or cutaneous MZL associated with heavy infiltrations of IgG4 plasma cells or arising from an underlying IgG4-related disease [69]. To the best of our knowledge, similar features have not yet been reported in the context of pulmonary MALT lymphomas. In difficult cases, molecular based methods for B-cell clonality and interphase FISH are useful tools to distinguish reactive conditions from lymphoma.

A few cases of synchronous occurrence of lung adenocarcinoma and pulmonary MALT lymphomas have been reported in the literature as already described in gastric MALT lymphomas [70, 71]. Although this event is very rare, clinicians and pathologists should be aware of the possible association of these two diseases.

\section{Prognosis and treatment}

Pre-therapeutic staging

Lymph node lymphoma with secondary dissemination to the lungs can be ruled out using a CT scan with contrast medium injection of the chest, abdomen and pelvis (table 4). Bone marrow biopsy is not essential, but may show MALT lymphoma dissemination in $13-30 \%$ of cases (figure 3) [7, 35, 72-74]. Similarly, concomitant disease in other mucosa-associated lymphoid sites is present in $25-35 \%$ of cases (figure 3 ) [73-75], and is more frequently observed in nondigestive MALT lymphomas. In a recent study of 63 
TABLE 4 Recommended procedures for initial staging of patients with disseminated mucosa-associated lymphoid tissue lymphoma according to the European Society for Medical Oncology consensus conference

Mandatory

Recommended

Optional

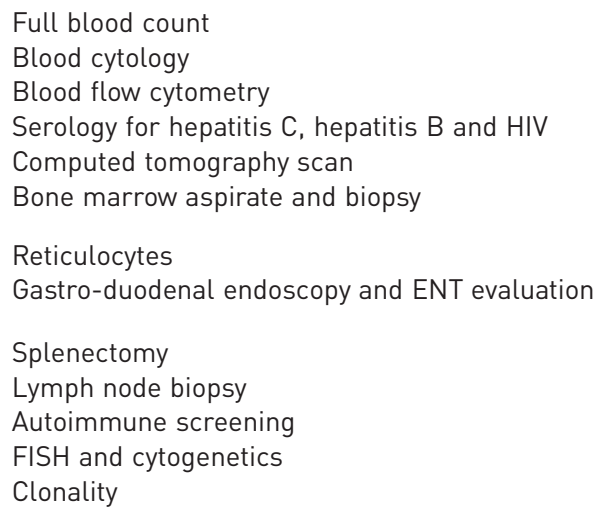

ENT: ear, nose and throat; FISH: fluorescent in situ hybridisation. Information from [86].

MALT lymphoma cases, 50\% exhibited extrapulmonary involvement, 33\% stomach involvement and 14\% bone marrow involvement [35]. Other mucosal sites must be assessed in symptomatic patients only, these sites include the eyes, ears, nose and throat, in addition to magnetic resonance imaging or ultrasound of the salivary and lacrimal glands, if there is any doubt, and gastroscopy and colonoscopy. Some cases may require evaluation of small bowel transit.

Positron emission tomography (PET) using 18F-2-fluoro-2-deoxy-D-glucose (FDG) has yet to be investigated in detail. Its sensitivity and specificity can vary depending on the organ under consideration. PET-FDG assessment of the stomach appears to be associated with high rates of false-negatives, achieving a sensitivity of between 50 and $89 \%$ [76]. When assessing pulmonary disease it produces better results, with a sensitivity of between 80 and 100\% [77, 78]. PET-FDG cannot enable assessment of bone marrow involvement [35], although can detect plasmacytic differentiation with higher sensitivity [79].

The only laboratory tests that are useful in pretreatment screening are lactate dehydrogenase levels, serum electrophoresis and immunoelectrophoresis. Monoclonal gammopathy, which is present in eight out of 10 IgM-type cases, is also found in $20-60 \%$ of MALT lymphoma cases. It is detected more frequently if plasmacytic differentiation is revealed [36, 38-40] and in extrapulmonary disease cases [35]. Finally, increased $\beta 2$-microglobulin level appears to be an independent factor associated with poor prognosis [73].

\section{Prognostic factors}

The prognosis for patients with MALT lymphomas is good, with overall 5-year survival rates surpassing $80 \%$ and a median survival of over 10 years [34-40, 60, 65, 73-75, 80]. MALT lymphoma patients actually benefit from longer overall survival than patients with nodal or spleen MZL [7]. However, the survival of patients with MALT lymphoma has not been demonstrated to be equivalent to that of the general population $[33,65]$. The median survival of patients exhibiting MALT lymphoma of the digestive tract does not differ from that of other sites, yet progression-free survival seems to be shorter for diseases at other sites, particularly the lungs [72]. A long period of monitoring is required in these cases, as almost $50 \%$ of patients experience disease recurrence, either in the same location or outside the thoracic region $[36,40,60,65,67],>2$ years after surgical resection.

The prognostic factors for MALT lymphomas have not yet been clearly demonstrated. None of the factors like sex, delay to diagnosis, symptom presence, whether or not the lesions were bilateral, extrapulmonary involvement or medullar location offered prognostic power [35]. In a multivariate analysis including all disease sites, elevated $\beta 2$-microglobulin levels [73] and stage IV classification according to the Ann Arbor system [81] were found to influence prognosis. In a study of 63 patients with pulmonary MALT lymphoma, age and performance status were poor prognostic factors for overall survival [35]. A further retrospective study involving 48 MALT lymphoma patients failed to identify any prognostic factors at all [82]. In a retrospective cohort of lymphoma associated with Sjögren's syndrome, active Sjögren's syndrome was associated with worse prognosis. However, this cohort included both MALT lymphoma and DLBCL cases [83]. Very recently, Thieblemont et al. [84] proposed a simple and effective prognosis factor including only age $>70$ years, Ann Arbor stage $>2$ and elevated lactate dehydrogenase. In a cohort of 393 patients, these 
three factors, when added together, discriminated three risk groups with different 5-year progression-free survival $(78 \%, 63 \%$ and $29 \% ; \mathrm{p}<0.001)$ and 5 -year overall survival $(99 \%, 92 \%$ and $74 \% ; \mathrm{p}<0.001)$.

The transformation of MALT lymphoma to DLBCL has been suggested by the fact that the two histological subtypes could be observed on sequential biopsies in a single patient, with similar rearrangements of the $I G H$ genes and accumulation of genetic abnormalities [27, 34, 38, 40,61, 63, 85]. However, given the presence of $\mathrm{t}(11: 18)$, a more aggressive treatment strategy could be justified [29].

\section{Main therapeutic options}

The most recent recommendations have centred on the more frequent gastric MALT lymphoma [86, 87]. No microorganism has been identified that plays an equivalent role to $H$. pylori in gastric lymphoma. We are thus unable to use effective antibiotic treatment for pulmonary MALT lymphoma. However, a partial response has recently been reported in a patient with pulmonary MALT lymphoma, undergoing four courses of 14 days of clarithromycin ( $2 \mathrm{~g}$ per day) without evidence of any pathogen [88].

Current treatments include surgery, chemotherapy, immunotherapy and radiotherapy. It is not possible to assess the relative effectiveness of these treatments, as comparative groups do not exist, and even non-treatment could be considered [89]. Nevertheless, surgical resection or radiotherapy may be considered if the lesion is localised [36, 38, 90]. Radiotherapy may then offer the benefit of less morbidity [91, 92].

The use of chemotherapy alone is permitted in cases of bilateral or extrapulmonary disease, or in cases of disease recurrence or progression. Multiple-agent chemotherapy treatment, such as CHOP (cyclophosphamide, hydroxydaunorubicin, oncovin and prednisone), is not thought to be superior to single-agent chemotherapy treatment using either chlorambucil or fludarabine $[35,36]$. Furthermore, cyclophosphamide- or anthracycline-based chemotherapies were poor prognostic factors for progression-free survival in one study, in comparison with chlorambucil [35]. Anti-CD20 monoclonal antibodies (rituximab) are effective, producing a $70 \%$ response rate in MALT lymphoma irrespective of the disease site, yet they are associated with high disease recurrence rates (36\%) [93].

A prospective phase III study involved 231 patients not suitable for local therapy, who were initiated on a course of rituximab or rituximab-chlorambucil [94]. The primary objective was achieved, with significantly better 5-year event-free survival rates observed in the double-therapy group compared with the monotherapy group ( $68 \%$ versus 50\%; $\mathrm{p}=0.02$ ). Double-therapy increased the complete response rate (78\% versus $65 \%)$. The 5-year progression-free survival rate was increased in the double-therapy group, although not significantly [94]. The 5-year survival was not improved (89\% rate). Grade 3-4 neutropenia was more common in the double-therapy group, whereas infection and toxicity-related death rates were equivalent in both groups. Rituximab alone was also evaluated in a third arm that was opened as a secondary trial, the results of which are expected. In a retrospective cohort of gastric MALT lymphoma, the remission rate was $100 \%$ at 6 weeks when applying double-therapy, versus $45 \%$ with rituximab alone [29]. In the same cohort, the complete response rate after 104 weeks of chlorambucil alone was $78 \%$ (20 out of 27) versus $39 \%$ in patients with and without the $t(11: 18)$, respectively [95]. However, there is no data available on pulmonary MALT lymphoma cases, despite the common presence of $\mathrm{t}(11: 18)$ in this setting. Alternative therapies that have proven antitumoral effects are currently available, such as purine analogues (fludarabine and cladribine), pentostatin, nuclear factor- $\mathrm{B}$ inhibitor (bortezomib) or multiple-agent chemotherapy with chlorambucil/mitoxantrone/prednisone or bendamustine/rituximab [87, 96, 97]. However, the respective value of each treatment is difficult to estimate, particularly considering their side-effects [98]. Lenalidomide or bortezomib have also been evaluated as second-line therapy [99-103].

Finally, local therapy (radiotherapy or surgery) should be considered when feasible in localised disease. Medical therapy must take into consideration age, symptoms, dissemination and performance status, and a watch-and-wait attitude could potentially be the best solution. The first line therapy that is actually most used is rituximab-chlorambucil therapy. However, one should consider the increased cost and the risk of haematological complications compared with giving chlorambucil alone as an option. Ultimately a wait and see attitude may be proposed in asymptomatic patients with limited disease, particularly among elderly patients or patients with comorbidities.

\section{Conclusion}

Significant progress has been made in identifying the oncogenic mechanisms involved in the development of pulmonary MALT lymphoma. To date, no infectious agent has been isolated as the cause for pulmonary MALT lymphomas, which may play an equivalent role to $H$. pylori in the development of gastric MALT lymphomas. The diagnosis of clonal lymphoproliferative disease has also benefited from using immunohistochemistry and molecular biological techniques. The potential contribution of these techniques 
should be more widely evaluated, in particular using bronchoscopic biopsy with small specimens in order to avoid traumatic thoracotomy procedures that are, at times, performed purely for diagnostic purposes.

In the absence of randomised trials specifically focused on pulmonary MALT lymphoma, the same treatment is currently offered for all MALT lymphoma types, regardless of the localisation. When there is other localisation or respiratory contraindications, surgery or radiotherapy should be considered. Otherwise rituximab-chlorambucil should be used on a case-by-case basis, and in some instances, simply monitoring the patient may be the most appropriate approach.

\section{References}

1 Cadranel J, Wislez M, Antoine M. Primary pulmonary lymphoma. Eur Respir J 2002; 20: 750-762.

2 Isaacson PG, Norton AJ. Extranodal Lymphomas. New York, Churchill Livingstone, 1994.

3 Freeman C, Berg JW, Cutler SJ. Occurrence and prognosis of extranodal lymphomas. Cancer 1972; 29: 252-260.

4 Jaffe E, Travis W. Lymphomatoid Granulomatosis and Lymphoproliferative Disorders of the Lung. Philaldelphia, Lippincott, 1991.

5 Swerdlow SH, Campo E, Harris NL, et al. World Health Organization Classification of Tumours of Haematopoietic and Lymphoid Tissues. 4th Edn. Geneva, World Health Organization, 2008.

6 Harris NL, Jaffe ES, Stein H, et al. A revised European-American classification of lymphoid neoplasms: a proposal from the International Lymphoma Study Group. Blood 1994; 84: 1361-1392.

7 Nathwani BN, Anderson JR, Armitage JO, et al. Marginal zone B-cell lymphoma: a clinical comparison of nodal and mucosa-associated lymphoid tissue types. Non-Hodgkin's Lymphoma Classification Project. J Clin Oncol 1999; 17: 2486-2492.

8 Remstein ED, James CD, Kurtin PJ. Incidence and subtype specificity of API2-MALT1 fusion translocations in extranodal, nodal, and splenic marginal zone lymphomas. Am J Pathol 2000; 156: 1183-1188.

9 Campo E, Miquel R, Krenacs L, et al. Primary nodal marginal zone lymphomas of splenic and MALT type. Am J Surg Pathol 1999; 23: 59-68.

10 Campo E, Swerdlow SH, Harris NL, et al. The 2008 WHO classification of lymphoid neoplasms and beyond: evolving concepts and practical applications. Blood 2011; 117: 5019-5032.

11 A clinical evaluation of the International Lymphoma Study Group classification of non-Hodgkin's lymphoma. The Non-Hodgkin's Lymphoma Classification Project. Blood 1997; 89: 3909-3918.

12 Suarez F, Lortholary O, Hermine O, et al. Infection-associated lymphomas derived from marginal zone B cells: a model of antigen-driven lymphoproliferation. Blood 2006; 107: 3034-3044.

13 Borie R, Cadranel J, Guihot A, et al. Pulmonary manifestations of human herpesvirus-8 during HIV infection. Eur Respir J 2013; 42: 1105-1118.

14 Amedei A, Bergman MP, Appelmelk BJ, et al. Molecular mimicry between Helicobacter pylori antigens and $\mathrm{H}^{+}$, $\mathrm{K}^{+}$-adenosine triphosphatase in human gastric autoimmunity. J Exp Med 2003; 198: 1147-1156.

15 Parsonnet J, Hansen S, Rodriguez L, et al. Helicobacter pylori infection and gastric lymphoma. N Engl J Med 1994; 330: 1267-1271.

16 Baumgaertner I, Copie-Bergman C, Levy M, et al. Complete remission of gastric Burkitt's lymphoma after eradication of Helicobacter pylori. World J Gastroenterol 2009; 15: 5746-5750.

17 Raderer M, Wöhrer S, Kiesewetter B, et al. Antibiotic treatment as sole management of Helicobacter pylori-negative gastric MALT lymphoma: a single center experience with prolonged follow-up. Ann Hematol 2015; 94: 969-973.

18 Bertoni F, Zucca E. State-of-the-art therapeutics: marginal-zone lymphoma. J Clin Oncol 2005; 23: 6415-6420.

19 Ferry JA. Extranodal lymphoma. Arch Pathol Lab Med 2008; 132: 565-578.

20 Chanudet E, Zhou Y, Bacon CM, et al. Chlamydia psittaci is variably associated with ocular adnexal MALT lymphoma in different geographical regions. J Pathol 2006; 209: 344-351.

21 Adam P, Czapiewski P, Colak S, et al. Prevalence of Achromobacter xylosoxidans in pulmonary mucosa-associated lymphoid tissue lymphoma in different regions of Europe. Br J Haematol 2014; 164: 804-810.

22 Foulongne V, Sauvage V, Hebert C, et al. Human skin microbiota: high diversity of DNA viruses identified on the human skin by high throughput sequencing. PLoS One 2012; 7: e38499.

23 Lecuit M, Eloit M. The diagnosis of infectious diseases by whole genome next generation sequencing: a new era is opening. Front Cell Infect Microbiol 2014; 4: 25

24 Ekström Smedby K, Vajdic CM, Falster M, et al. Autoimmune disorders and risk of non-Hodgkin lymphoma subtypes: a pooled analysis within the InterLymph Consortium. Blood 2008; 111: 4029-4038.

25 Bracci PM, Benavente Y, Turner JJ, et al. Medical history, lifestyle, family history, and occupational risk factors for marginal zone lymphoma: the InterLymph Non-Hodgkin Lymphoma Subtypes Project. J Natl Cancer Inst Monogr 2014; 2014: 52-65.

26 Remstein ED, Dogan A, Einerson RR, et al. The incidence and anatomic site specificity of chromosomal translocations in primary extranodal marginal zone B-cell lymphoma of mucosa-associated lymphoid tissue (MALT lymphoma) in North America. Am J Surg Pathol 2006; 30: 1546-1553.

27 Farinha P, Gascoyne RD. Molecular pathogenesis of mucosa-associated lymphoid tissue lymphoma. J Clin Oncol 2005; 23: 6370-6378.

28 Streubel B, Simonitsch-Klupp I, Müllauer L, et al. Variable frequencies of MALT lymphoma-associated genetic aberrations in MALT lymphomas of different sites. Leukemia 2004; 18: 1722-1726.

29 Lévy M, Copie-Bergman C, Amiot A, et al. Rituximab and chlorambucil versus rituximab alone in gastric mucosa-associated lymphoid tissue lymphoma according to $\mathrm{t}(11 ; 18)$ status: a monocentric non-randomized observational study. Leuk Lymphoma 2013; 54: 940-944.

30 Li Z, Wang H, Xue L, et al. Emu-BCL10 mice exhibit constitutive activation of both canonical and noncanonical NF-kappaB pathways generating marginal zone (MZ) B-cell expansion as a precursor to splenic MZ lymphoma. Blood 2009; 114: 4158-4168.

31 Sagaert X, Theys T, De Wolf-Peeters C, et al. Splenic marginal zone lymphoma-like features in API2-MALT1 transgenic mice that are exposed to antigenic stimulation. Haematologica 2006; 91: 1693-1696. 
Baens M, Fevery S, Sagaert X, et al. Selective expansion of marginal zone B cells in Emicro-API2-MALT1 mice is linked to enhanced IkappaB kinase gamma polyubiquitination. Cancer Res 2006; 66: 5270-5277.

Kurtin PJ, Myers JL, Adlakha $\mathrm{H}$, et al. Pathologic and clinical features of primary pulmonary extranodal marginal zone B-cell lymphoma of MALT type. Am J Surg Pathol 2001; 25: 997-1008.

Li G, Hansmann ML, Zwingers T, et al. Primary lymphomas of the lung: morphological, immunohistochemical and clinical features. Histopathology 1990; 16: 519-531.

Borie R, Wislez M, Thabut G, et al. Clinical characteristics and prognostic factors of pulmonary MALT lymphoma. Eur Respir J 2009; 34: 1408-1416.

Cordier JF, Chailleux E, Lauque D, et al. Primary pulmonary lymphomas. A clinical study of 70 cases in nonimmunocompromised patients. Chest 1993; 103: 201-208.

Herbert A, Wright DH, Isaacson PG, et al. Primary malignant lymphoma of the lung: histopathologic and immunologic evaluation of nine cases. Hum Pathol 1984; 15: 415-422.

Kennedy JL, Nathwani BN, Burke JS, et al. Pulmonary lymphomas and other pulmonary lymphoid lesions. A clinicopathologic and immunologic study of 64 patients. Cancer 1985; 56: 539-552.

Le Tourneau A, Audouin J, Garbe L, et al. Primary pulmonary malignant lymphoma, clinical and pathological findings, immunocytochemical and ultrastructural studies in 15 cases. Hematol Oncol 1983; 1: 49-60.

L'Hoste RJ Jr, Filippa DA, Lieberman PH, et al. Primary pulmonary lymphomas. A clinicopathologic analysis of 36 cases. Cancer 1984; 54: 1397-1406. 10 patients. J Comput Assist Tomogr 2000; 24: 30-34.

Wislez M, Cadranel J, Antoine M, et al. Lymphoma of pulmonary mucosa-associated lymphoid tissue: CT scan findings and pathological correlations. Eur Respir J 1999; 14: 423-429.

Zamora AC, White DB, Sykes AG, et al. Amyloid-associated cystic lung disease. Chest 2015 [in press; DOI: 10.1378/chest.15-1539].

Colombat M, Caudroy S, Lagonotte E, et al. Pathomechanisms of cyst formation in pulmonary light chain deposition disease. Eur Respir J 2008; 32: 1399-1403.

Yildirim F, Kara I, Yildiz S, et al. A rare cause of cavitary lesion in the lung: Richter's transformation. Case Rep Pulmonol 2015; 2015: 945268.

Drent M, Wagenaar SS, Mulder PH, et al. Bronchoalveolar lavage fluid profiles in sarcoidosis, tuberculosis, and non-Hodgkin's and Hodgkin's disease. An evaluation of differences. Chest 1994; 105: 514-519.

Costabel U, Bross KJ, Matthys H. Diagnosis by bronchoalveolar lavage of cause of pulmonary infiltrates in haematological malignancies. Br Med J (Clin Res Ed) 1985; 290: 1041.

Pisani RJ, Witzig TE, Li CY, et al. Confirmation of lymphomatous pulmonary involvement by immunophenotypic and gene rearrangement analysis of bronchoalveolar lavage fluid. Mayo Clin Proc 1990; 65: 651-656.

Schwaiger A, Prior C, Weyrer K, et al. Non-Hodgkin's lymphoma of the lung diagnosed by gene rearrangement from bronchoalveolar lavage fluid: a fast and noninvasive method. Blood 1991; 77: 2538-2539.

Shiota T, Chiba W, Ikeda S, et al. Gene analysis of pulmonary pseudolymphoma. Chest 1993; 103: $335-338$.

Subramanian D, Albrecht S, Gonzalez JM, et al. Primary pulmonary lymphoma. Diagnosis by immunoglobulin gene rearrangement study using a novel polymerase chain reaction technique. Am Rev Respir Dis 1993; 148: $222-226$.

Zompi S, Couderc LJ, Cadranel J, et al. Clonality analysis of alveolar B lymphocytes contributes to the diagnostic strategy in clinical suspicion of pulmonary lymphoma. Blood 2004; 103: 3208-3215.

Borie R, Wislez M, Antoine M, et al. Clonality and phenotyping analysis of alveolar lymphocytes is suggestive of pulmonary MALT lymphoma. Respir Med 2011; 105: 1231-1237.

Kido T, Yatera K, Noguchi S, et al. Detection of MALT1 gene rearrangements in BAL fluid cells for the diagnosis of pulmonary mucosa-associated lymphoid tissue lymphoma. Chest 2012; 141: 176-182.

Nunez AL, Jhala NC, Carroll AJ, et al. Endoscopic ultrasound and endobronchial ultrasound-guided fine-needle aspiration of deep-seated lymphadenopathy: analysis of 1338 cases. Cytojournal 2012; 9: 14.

Kennedy MP, Jimenez CA, Bruzzi JF, et al. Endobronchial ultrasound-guided transbronchial needle aspiration in the diagnosis of lymphoma. Thorax 2008; 63: 360-365.

Steinfort DP, Conron M, Tsui A, et al. Endobronchial ultrasound-guided transbronchial needle aspiration for the evaluation of suspected lymphoma. J Thorac Oncol 2010; 5: 804-809.

Wells AU, Costabel U, Poletti V, et al. Challenges in IPF diagnosis, current management and future perspectives. Sarcoidosis Vasc Diffuse Lung Dis 2015; 32: Suppl., 28-35.

Poletti V, Gurioli C, Piciucchi S, et al. Intravascular large B cell lymphoma presenting in the lung: the diagnostic value of transbronchial cryobiopsy. Sarcoidosis Vasc Diffuse Lung Dis 2015; 31: 354-358.

Addis BJ, Hyjek E, Isaacson PG. Primary pulmonary lymphoma: a re-appraisal of its histogenesis and its relationship to pseudolymphoma and lymphoid interstitial pneumonia. Histopathology 1988; 13 : 1-17.

Nicholson AG, Wotherspoon AC, Diss TC, et al. Pulmonary B-cell non-Hodgkin's lymphomas. The value of immunohistochemistry and gene analysis in diagnosis. Histopathology 1995; 26: 395-403.

Bégueret H, Vergier B, Parrens M, et al. Primary lung small B-cell lymphoma versus lymphoid hyperplasia: evaluation of diagnostic criteria in 26 cases. Am J Surg Pathol 2002; 26: 76-81.

Fiche M, Caprons F, Berger F, et al. Primary pulmonary non-Hodgkin's lymphomas. Histopathology 1995; 26: 529-537.

Turner RR, Colby TV, Doggett RS. Well-differentiated lymphocytic lymphoma. A study of 47 patients with primary manifestation in the lung. Cancer 1984; 54: 2088-2096.

Koss MN, Hochholzer L, Nichols PW, et al. Primary non-Hodgkin's lymphoma and pseudolymphoma of lung: a study of 161 patients. Hum Pathol 1983; 14: 1024-1038.

Foulet A, Petrella T, Viard H, et al. Lesions lympho-epitheliales induites par des plasmocytes dans un lymphome MALT du poumon [Lympho-epithelial lesions induced by plasma cells in a pulmonary MALT lymphoma]. Ann Pathol 1994; 14: 36-40.

Peterson H, Snider HL, Yam LT, et al. Primary pulmonary lymphoma. A clinical and immunohistochemical study of six cases. Cancer 1985; 56: 805-813. 

study of 14 cases. Am J Surg Pathol 2000; 24: 587-597.

69 Lee MJ, Kim N, Choe JY, et al. Clinicopathological analysis of ocular adnexal extranodal marginal zone B-cell lymphoma with IgG4-positive cells. PLoS One 2015; 10: e0131458.

70 Copie-Bergman C, Locher C, Levy M, et al. Metachronous gastric MALT lymphoma and early gastric cancer: is residual lymphoma a risk factor for the development of gastric carcinoma? Ann Oncol 2005; 16: 1232-1236.

71 Tian P, Wang Y, Wan C, et al. CT-guided needle biopsy in the diagnosis of lung adenocarcinoma accompanied by extranodal marginal zone lymphoma of mucosa-associated lymphoid tissue: a rare combination. Int J Clin Exp Pathol 2015; 8: 2074-2078.

72 Thieblemont C, Bastion Y, Berger F, et al. Mucosa-associated lymphoid tissue gastrointestinal and nongastrointestinal lymphoma behavior: analysis of 108 patients. J Clin Oncol 1997; 15: 1624-1630.

73 Thieblemont C, Berger F, Dumontet C, et al. Mucosa-associated lymphoid tissue lymphoma is a disseminated disease in one third of 158 patients analyzed. Blood 2000; 95: 802-806.

74 Zinzani PL, Magagnoli M, Galieni P, et al. Nongastrointestinal low-grade mucosa-associated lymphoid tissue lymphoma: analysis of 75 patients. J Clin Oncol 1999; 17: 1254

75 Raderer M, Vorbeck F, Formanek M, et al. Importance of extensive staging in patients with mucosa-associated lymphoid tissue (MALT)-type lymphoma. Br J Cancer 2000; 83: 454-457.

76 Enomoto K, Hamada K, Inohara H, et al. Mucosa-associated lymphoid tissue lymphoma studied with FDG-PET: a comparison with CT and endoscopic findings. Ann Nucl Med 2008; 22: 261-267.

77 Beal KP, Yeung HW, Yahalom J. FDG-PET scanning for detection and staging of extranodal marginal zone lymphomas of the MALT type: a report of 42 cases. Ann Oncol 2005; 16: 473-480.

78 Bae YA, Lee KS, Han J, et al. Marginal zone B-cell lymphoma of bronchus-associated lymphoid tissue: imaging findings in 21 patients. Chest 2008; 133: 433-440.

79 Hoffmann M, Wöhrer S, Becherer A, et al. 18F-Fluoro-deoxy-glucose positron emission tomography in lymphoma of mucosa-associated lymphoid tissue: histology makes the difference. Ann Oncol 2006; 17: 1761-1765.

80 Stefanovic A, Morgensztern D, Fong T, et al. Pulmonary marginal zone lymphoma: a single centre experience and review of the SEER database. Leuk Lymphoma 2008; 49: 1311-1320.

81 Zucca E, Conconi A, Pedrinis E, et al. Nongastric marginal zone B-cell lymphoma of mucosa-associated lymphoid tissue. Blood 2003; 101: 2489-2495.

82 Ferraro P, Trastek VF, Adlakha H, et al. Primary non-Hodgkin's lymphoma of the lung. Ann Thorac Surg 2000 69: 993-997.

83 Papageorgiou A, Ziogas DC, Mavragani CP, et al. Predicting the outcome of Sjogren's syndrome-associated non-hodgkin's lymphoma patients. PLoS One 2015; 10: e0116189.

84 Thieblemont C, Thieblemont C, Conconi A, et al. A simple and effective MALT lymphoma - specific prognostic index generated from the dataset of IELSG19 controlled clinical trial. Hematol Oncol 2015; 33: Suppl. 1, 167.

85 Chan JK, Ng CS, Isaacson PG. Relationship between high-grade lymphoma and low-grade B-cell mucosa-associated lymphoid tissue lymphoma (MALToma) of the stomach. Am J Pathol 1990; 136: 1153-1164.

86 Dreyling M, Thieblemont C, Gallamini A, et al. ESMO Consensus conferences: guidelines on malignant lymphoma. part 2: marginal zone lymphoma, mantle cell lymphoma, peripheral T-cell lymphoma. Ann Oncol 2013; 24: 857-877.

87 Zucca E, Stathis A, Bertoni F. The management of nongastric MALT lymphomas. Oncology (Williston Park) 2014; 28: 86-93.

88 Ferreri AJ, Sassone M, Kiesewetter B, et al. High-dose clarithromycin is an active monotherapy for patients with relapsed/refractory extranodal marginal zone lymphoma of mucosa-associated lymphoid tissue (MALT): the HD-K phase II trial. Ann Oncol 2015; 26: 1760-1765.

89 Wöhrer S, Kiesewetter B, Fischbach J, et al. Retrospective comparison of the effectiveness of various treatment modalities of extragastric MALT lymphoma: a single-center analysis. Ann Hematol 2014; 93: 1287-1295.

90 Girinsky T, Paumier A, Ferme C, et al. Low-dose radiation treatment in pulmonary mucosa-associated lymphoid tissue lymphoma: a plausible approach? A single-institution experience in 10 patients. Int J Radiat Oncol Biol Phys 2012; 83: e385-e389.

91 Wang L, Xia ZJ, Zhang YJ, et al. Radical surgery may be not an optimal treatment approach for pulmonary MALT lymphoma. Tumour Biol 2015; 36: 6409-6416.

92 Nakamura S, Sugiyama T, Matsumoto T, et al. Long-term clinical outcome of gastric MALT lymphoma after eradication of Helicobacter pylori: a multicentre cohort follow-up study of 420 patients in Japan. Gut 2012; 61: 507-513.

93 Conconi A, Martinelli G, Thieblemont C, et al. Clinical activity of rituximab in extranodal marginal zone B-cell lymphoma of MALT type. Blood 2003; 102: 2741-2745.

94 Zucca E, Conconi A, Laszlo D, et al. Addition of rituximab to chlorambucil produces superior event-free survival in the treatment of patients with extranodal marginal-zone B-cell lymphoma: 5-year analysis of the IELSG-19 randomized study. J Clin Oncol 2013; 31: 565-572.

95 Amiot A, Lévy M, Copie-Bergman C, et al. Rituximab, alkylating agents or combination therapy for gastric mucosa-associated lymphoid tissue lymphoma: a monocentric non-randomised observational study. Aliment Pharmacol Ther 2014; 39: 619-628.

96 Zinzani PL, Stefoni V, Musuraca G, et al. Fludarabine-containing chemotherapy as frontline treatment of nongastrointestinal mucosa-associated lymphoid tissue lymphoma. Cancer 2004; 100: 2190-2194.

97 Wöhrer S, Drach J, Hejna $\mathrm{M}$, et al. Treatment of extranodal marginal zone B-cell lymphoma of mucosa-associated lymphoid tissue (MALT lymphoma) with mitoxantrone, chlorambucil and prednisone (MCP). Ann Oncol 2003; 14: 1758-1761.

98 Jäger G, Höfler G, Linkesch W, et al. Occurrence of a myelodysplastic syndrome (MDS) during first-line 2-chloro-deoxyadenosine (2-CDA) treatment of a low-grade gastrointestinal MALT lymphoma. Case report and review of the literature. Haematologica 2004; 89: ECR01.

99 Salar A, Domingo-Domenech E, Estany C, et al. Combination therapy with rituximab and intravenous or oral fludarabine in the first-line, systemic treatment of patients with extranodal marginal zone B-cell lymphoma of the mucosa-associated lymphoid tissue type. Cancer 2009; 115: 5210-5217. 
100 Salar A, Avivi I, Bittner B, et al. Comparison of subcutaneous versus intravenous administration of rituximab as maintenance treatment for follicular lymphoma: results from a two-stage, phase IB study. J Clin Oncol 2014; 32: $1782-1791$.

101 Troch M, Kiesewetter B, Willenbacher W, et al. Rituximab plus subcutaneous cladribine in patients with extranodal marginal zone B-cell lymphoma of mucosa-associated lymphoid tissue: a phase II study by the Arbeitsgemeinschaft Medikamentose Tumortherapie. Haematologica 2013; 98: 264-268.

102 Troch M, Jonak C, Müllauer L, et al. A phase II study of bortezomib in patients with MALT lymphoma. Haematologica 2009; 94: 738-742.

103 Kiesewetter B, Troch M, Dolak W, et al. A phase II study of lenalidomide in patients with extranodal marginal zone B-cell lymphoma of the mucosa associated lymphoid tissue (MALT lymphoma). Haematologica 2013; 98 : 353-356.

104 Lycke N. Recent progress in mucosal vaccine development: potential and limitations. Nat Rev Immunol 2012; 12: 592-605. 